\title{
Preliminary results of bio-optical investigations at Lake Baikal
}

\section{Churilova T.Ya. ${ }^{1}{ }^{* \oplus}$, Moiseeva N.A. ${ }^{1}$, Latushkin A.A. ${ }^{2}$, Suslin V.V. ${ }^{2}$, Usoltseva M.V. ${ }^{3}$, Zakharova Yu.R. ${ }^{3}$, Titova L.A. ${ }^{3}$, Gnatovsky R.Yu. ${ }^{3}$, Blinov V.V. ${ }^{3}$}

${ }^{1}$ Kovalevsky Institute of Marine Biological Research, RAS, Nakhimov Ave., 2, Sevastopol, 299011, Russia

${ }^{2}$ Marine Hydrophysical Institute RAS, Kapitanskay Str., 2, Sevastopol, 299011, Russia

${ }^{3}$ Limnological Institute, Siberian Branch of the Russian Academy of Sciences, Ulan-Batorskaya Str., 3, Irkutsk, 664033, Russia

\begin{abstract}
The preliminary results of complex bio-optical investigations carried out at Lake Baikal in July 2018 showed high variability in the light absorption properties of all optically active components, as well as their relation with hydrophysical characteristics. Vertical distribution of chlorophyll a was characterized by the presence of a maximum near the bottom of the euphotic zone. In this deep chlorophyll maximum layer, there were specific features of phytoplankton light absorption spectra reflecting the abundance of phycobilin-containing blue-green algae in the phytoplankton community.
\end{abstract}

Keywords: chlorophyll, light absorption, optically active components, blue-green algae, downwelling radiance, Lake Baikal

\section{Introduction}

Remote sensing provides unique opportunity in the observation of the World Ocean due to high spatial and temporal resolution of optical scanner data. In fact, it allows developing a system for operative (real-time) ecological monitoring, which cannot be realized by traditional approach to in situ measurements. Operative remote assessment of the water quality and productivity indicators in Lake Baikal could be used for solving the current ecological problems (Fietz et al., 2005; Hampton et al., 2008; Bondarenko et al., 2012; Belykh et al., 2016; Bondarenko and Logacheva, 2016; Timoshkin et al., 2016). Correct transformation of remote sensing data to the ecological indicators requires an application of regional algorithms developed on the basis of biooptical properties of a particular water body. The light absorption by phytoplankton $\left(a_{\mathrm{ph}}(\lambda)\right)$, by non-algal particles $\left(a_{\mathrm{NAP}}(\lambda)\right)$ and by colored dissolved organic matter $\left(a_{\mathrm{CDOM}}(\lambda)\right)$ are the most significant bio-optical properties for the algorithms (Suslin and Churilova, 2016). To adapt three-band algorithm for assessment of chlorophyll $a$ concentration and colored detrital matter $\left(a_{\mathrm{CDM}}(\lambda)=a_{\mathrm{NAP}}(\lambda)+a_{\mathrm{CDOM}}(\lambda)\right)$ in the upper layer of Lake Baikal (Case 2 waters), it is necessary to investigate spatial-temporal variability in $a_{\mathrm{ph}}(\lambda)$, $a_{\mathrm{NAP}}(\lambda)$ and $a_{\mathrm{CDOM}}(\lambda)$, to parameterize light absorption by all in-water optically active components and to assess relative contribution of each components to total light absorption.

The aim of the paper is to present preliminary results of complex bio-optical investigations carried out for the first time in Lake Baikal in August 2018.

\section{Methods}

Bio-optical investigations were carried in Lake Baikal during the scientific cruise onboard RV "G.Yu. Vereshchagin" from 24 to 31 July 2018. The SBE-911 plus (Sea Bird Electronics) conductivity, temperature, depth (CTD) probe provided temperature and salinity profiles, and the rosette included $24 \times 5$-liter Niskin bottles for water sampling. Downwelling radiance $\left(E_{d}(\lambda)\right)$ was measured at 7 spectral bands within visible domain (within photosynthetically active radiation, PAR) with spectrometer designed and made in Marine Hydrophysical Institute (Sevastopol, Russia). Water samples were collected at several depths chosen based on the temperature and $E_{d}(\lambda)$ profiles.

Samples for pigment and particulate light absorption analysis were gently (vacuum $<25 \mathrm{kPa}$ ) filtered through 25-mm GF/F (Whatman) filters and stored in liquid nitrogen for measurements in the laboratory. Samples were extracted in $90 \%$ acetone overnight in refrigerator, and then samples were treated with a vibration mixer (FALK Falc instruments, Italy) and centrifuged. Chlorophyll and phaeopigment concentrations were determined spectrophotometrically (Jeffry and Humphry, 1975; Lorenzen, 1967) with dual- 
beam spectrophotometer Lambda 35 (Perkin Elmer).

Light absorption by particles and by CDOM were measured in line with the NASA ocean color protocols (Mitchell et al., 2002), which was described in details in (Churilova et al., 2017). For particulate absorption, water samples were filtered under low vacuum $(<25$ $\mathrm{kPa}$ ) on $\mathrm{GF} / \mathrm{F}$ (Whatman) filters immediately after water sampling. The filters with samples were immediately frozen in liquid nitrogen and stored in a dewar until analysis in the laboratory. Optical density was measured with dual-beam spectrophotometer Lambda 35 (Perkin Elmer) equipped with an integrating sphere. Pigments were extracted with hot methanol (Kishino et al., 1985; Churilova et al., 2018). The b-correction was performed as described in (Mitchell, 1990).

To measure CDOM light absorption, water samples were pre-filtered and then filtered under dim light through $0.2 \mu \mathrm{m}$ Sartorius membrane filter rinsed previously with $\sim 100 \mathrm{ml}$ of deionized water. The samples were stored at $-20^{\circ} \mathrm{C}$ until analysis in the laboratory. The measurements were conducted in $0.1 \mathrm{~m}$ quartz cell from 300 to $750 \mathrm{~nm}$ with dual-beam spectrophotometer Lambda 35 (Perkin Elmer). Spectral distribution of $a_{\mathrm{NAP}}(\lambda)$ and $a_{\mathrm{CDOM}}(\lambda)$ coefficients were described with exponential function (Babin et al., 2003). Spectral slopes $\left(S_{\mathrm{NAP}}\right.$ and $\left.S_{\mathrm{CDOM}}\right)$ were calculated by fitting a nonlinear model to data from the wavelength domain of $400-700$ and $350-500 \mathrm{~nm}$, respectively.

Phytoplankton species composition, abundance and biomass (micro- and nano- phytoplankton) were determined with the deposition method (Kiselev, 1969; Guide to hydrobiological monitoring ..., 1992) using light microscope Axiovert 200 (ZEISS, Germany) with Pixera Penguin 600CL camera. Samples were preserved with solution of Lugol and sodium acetate (Sadchikov, 2003). Cell volume and biomass were calculated according to (Makarova and Pichkily, 1970; Belykh et al., 2011).

\section{Results and discussion}

For the first time in Lake Baikal, complex biooptical investigations were carried out from July 24 to July 31 2018. Preliminary results were obtained for the surface layer (17 stations) and for a layer of $0-75$ $\mathrm{m}$ at the station 32 located in the middle of Maloye More Strait (mMM) of Lake Baikal. In the surface layer, chlorophyll $a$ in sum with phaeopigments (Chl- $a$ ) varied significantly $\left(0.58-5.3 \mathrm{mg} \mathrm{m}^{-3}\right)$. Bio-optical properties and species composition of phytoplankton community changed significantly from the surface to $\sim 75 \mathrm{~m}$ depth (Fig. 1-5). At the mMM station, thermocline was observed within 7-20 m layer with the maximum temperature gradient (MTG) located at $10 \mathrm{~m}$ (Fig. 1). Maximum values of Chl- $a$ were recorded below MTG and near the bottom of euphotic layer ( $~ 1 \%$ PAR) (Fig. 1).

Phytoplankton was analyzed at two depths (0 and $20 \mathrm{~m}$ ) of the mMM station. In the surface layer, phytoplankton biomass was generally represented by Synedra acus subsp. radians (Kutzing) Skabitschevsky (Bacillariaphyceae) and Gyrodinium helveticum
(Dinophyceae) (Fig. 2), which contributed 55\% and $35 \%$ to total biomass (micro- and nanofractions), respectively (Fig. 3). The phytoplankton biomass decreased slightly from surface layer $\left(280 \mathrm{mg} \mathrm{m}^{-3}\right)$ to

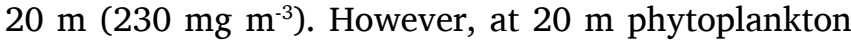
was mainly represented by another taxon compared to the surface phytoplankton. Below MTG (at 20m), Monoraphidium griffithii (Chlorophyceae) contributed $\sim 60 \%$ to total biomass.

Shape of spectrum and magnitude of $a_{\mathrm{ph}}(\lambda)$ coefficients was depth-dependent (Fig. 4). In the layer above MTG, the $a_{\mathrm{ph}}(\lambda)$ spectra were characterized by two main peaks: in blue $(\sim 438 \mathrm{~nm})$ and $\operatorname{red}(\sim 678 \mathrm{~nm})$ parts of the spectrum. The values of the chlorophyll $a$ specific absorption coefficient decreased with depth. The decrease was most significant in the blue maximum

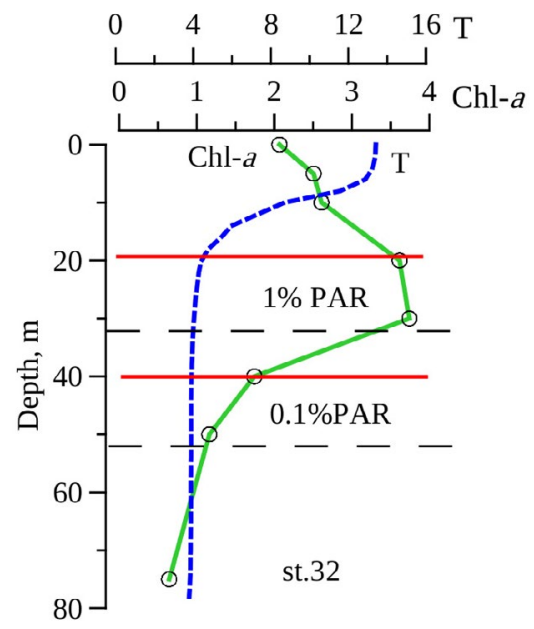

Fig. 1. Vertical distribution of chlorophyll $a$ concentration in sum with phaeopigments (Chl- $a, \mathrm{mg} \mathrm{m}^{-3}$ ) (circles, green line), temperature $\left(\mathrm{T},{ }^{\circ} \mathrm{C}\right)$ (blue dashed line) in the middle of Maloye More Strait of Lake Baikal (st. 32): black dashed lines indicate 1 and $0.1 \%$ level of photosynthetically active radiation (PAR); red lines - the layer, where phytoplankton light absorbance was characterized by the local maximum at $\sim 560 \mathrm{~nm}$.

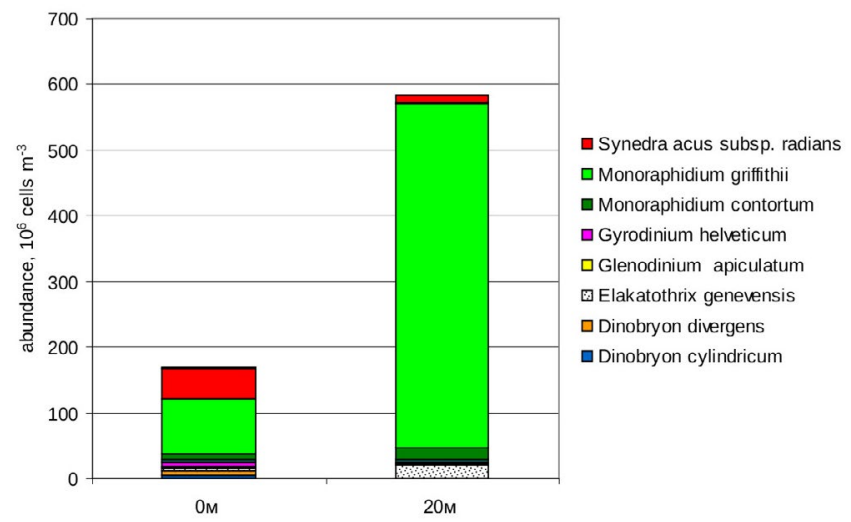

Fig. 2. The abundance of phytoplankton species at the station in the middle of Maloye More Strait (mMM) of Lake Baikal. 
of the spectrum (from 0.060 to $0.033 \mathrm{~m}^{2} \mathrm{mg}^{-1}$ ) than in the red (from 0.020 to $0.017 \mathrm{~m}^{2} \mathrm{mg}^{-1}$ ). In the layer below the thermocline shape of $a_{\mathrm{ph}}(\lambda)$, spectrum changed: a local absorption maximum was at $\sim 560 \mathrm{~nm}$. The local peak was most obvious at $\sim 30 \mathrm{~m}$ depth, where PAR was approxomately $1 \%$ of PAR incidence on the lake surface. This peak disappeared bellow $50 \mathrm{~m}$. The local peak at $560 \mathrm{~nm}$ was complimentary to the blue-green irradiance $(510-560 \mathrm{~nm})$ penetrated the bottom of the euphotic zone (1\% PAR) (Fig. 5). The absorbance at $\sim 560 \mathrm{~nm}$ is likely to be related with phycobillins, in particular, with phycoerythrin (Jeffrey et al., 1997; Six et al., 2007). Observed changes in the $a_{\mathrm{ph}}(\lambda)$ shape reflected the changes in the share of phycoerythrin in the total amount of the pigments (accessory pigments). Therefore, the relative abundance of phycoerythrin containing microalgae (cyanobacteria) changed with depth. At depths of 20-40 m, where the local absorption peak at $\sim 560 \mathrm{~nm}$ was obvious in absorption spectrum, the share of blue-green algae in the total biomass was sufficiently large; thus, the absorption of phycobilins was not masked by other pigments. Investigations in the Black Sea showed that the contribution of bluegreen algae to the total biomass of the phytoplankton community in deep chlorophyll maximum $(\sim 1 \%$ PAR) reached $\sim 50 \%$ (Churilova et al., 2018). In the present research, pico-fraction of phytoplankton was not estimated. However, phycobillins are likely to be contained in pigment complex of blue-green algae (picocyanobacteria). Analysis of the microand nanofractions of phytoplankton showed that dominating taxon (in biomass) changed from diatoms in the surface layer to green algae below the thermocline $(20 \mathrm{~m})$. Although the phytoplankton structure changed, the shape of $a_{\mathrm{ph}}(\lambda)$ spectra practically did not changed not taking into account local maximum at $\sim 560$ nm (Fig. 4). Absence of the notable effect of shift in dominating taxons on spectrum shape is due to the fact that absorbance bands of accessory pigments of these taxonomic groups are close (Jeffrey et al., 1997).

Spectral distribution of the $a_{\mathrm{NAP}}(\lambda)$ was described by the exponential function with the slope coefficient $\left(\mathrm{S}_{\mathrm{NAP}}\right)$ equal to $\sim 0.009 \mathrm{~nm}^{-1}$. The contribution of NAP to the total particulate absorption at $\sim 438 \mathrm{~nm}$ increased with depth from $\sim 10-15 \%$ to $\sim 30-40 \%$. The $a_{\text {CDOM }}(\lambda)$ spectral distribution was described by an exponential function with the slope coefficient $\left(\mathrm{S}_{\mathrm{CDOM}}\right)$ equal to $0.012-0.016 \mathrm{~nm}^{-1}$. The $a_{\mathrm{CDOM}}(\lambda)$ values at $\sim 438 \mathrm{~nm}$ were $0.090-0.26 \mathrm{~m}^{-1}$.

\section{Conclusion}

The preliminary results of complex bio-optical investigations carried out at Lake Baikal in July 2018 showed high variability in the light absorption properties of all optically active components, their relation with hydrophysical characteristics and phytoplankton species composition. These results underlined a necessity of detailed investigations of spatial variability in bio-optical properties at particular seasons accompanied by shift in dominating species in the phytoplankton community. Revealed regularities in

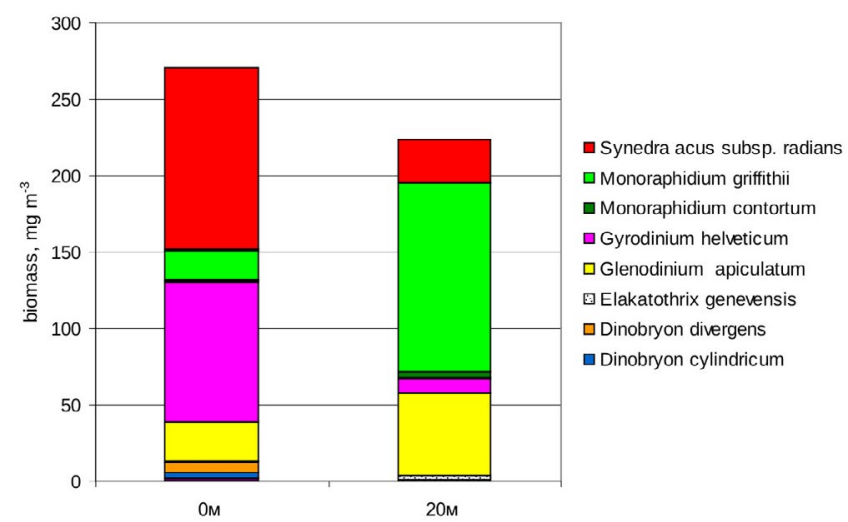

Fig. 3. The biomass of phytoplankton species at the station in the middle of Maloye More Strait (mMM) of Lake Baikal.

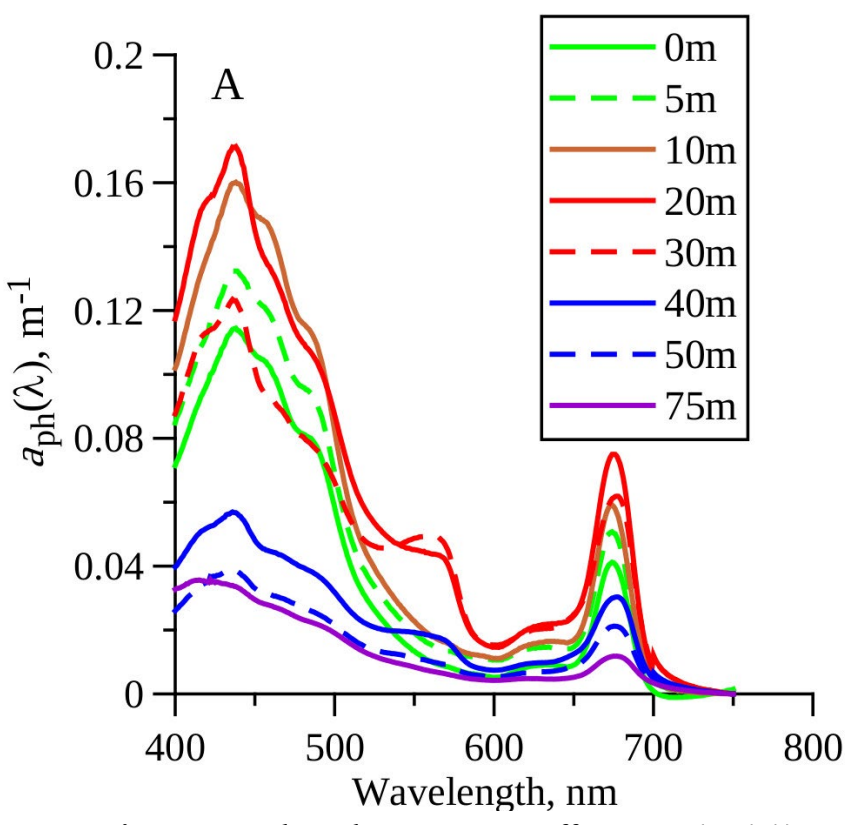

Fig. 4. Light absorption coefficients $\left(a_{\mathrm{ph}}(\lambda)\right)$ at different depths in the middle of Maloye More Strait of Lake Baikal (st.32).

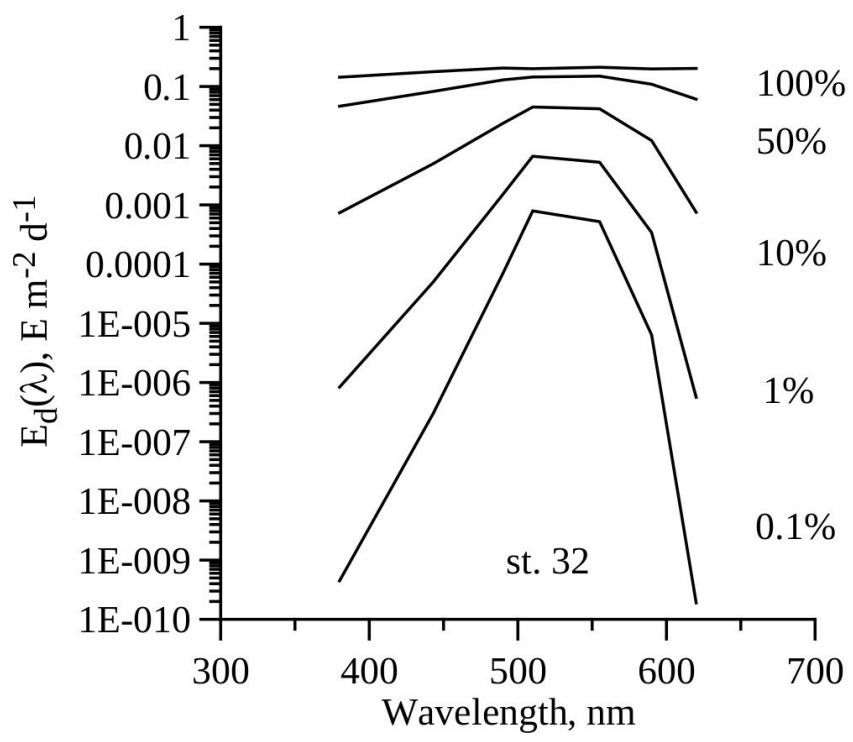

Fig. 5. Downwelling radiance $\left(\mathrm{E}_{\mathrm{d}}(\lambda)\right)$ at depths with different level $(100 ; 50 ; 10 ; 1 ; 0,1 \%)$ of photosynthetically available radiation in the middle of Maloye More Strait of Lake Baikal (st. 32). 
temporal and spatial variability in bio-optical properties will be used for development of regional algorithms, which are required for operative ecological monitoring of Lake Baikal based on remote sensing data.

\section{Acknowledgments}

The authors are very thankful to the crew of RV "G.Yu. Vereshchagin" for help in sampling during the cruise. The work was carried out within the framework of the state projects Nos. AAAA-A18-118020790229-7, 0827-2018-0002, AAAA-A16-116122110059-3.

\section{References}

Babin M., Stramski D., Ferrari G.M. et al. 2003. Variations in the light absorption coefficients of phytoplankton, nonalgal particles, and dissolved organic matter in coastal waters around Europe. Journal of Geophysical Research 108: 3211. DOI: 10.1029/ 2001JC000882

Belykh O.I., Bessudova A.Y., Gladkikh A.S. et al. 2011. Guidelines for the determination of the biomass of pelagic plankton species of Lake Baikal. Irkutsk: Publishing house of ISU. (in Russian).

Belykh O.I., Tikhonova I.V., Kuzmin A.V. et al. 2016. First detection of benthic cyanobacteria in Lake Baikal producing paralytic shellfish toxins. Toxicon 121: 36-40. DOI: 10.1016/j.toxicon.2016.08.015

Bondarenko N.A., Belykh O.I., Logacheva N.F. et al. 2012. Microalgae in the shore zone of Lake Baikal. The Bulletin of Irkutsk State University, Series «Biology, Ecology» 3: 88-102.

Bondarenko N.A., Logacheva N.F. 2016. Structural Changes in phytoplankton of the littoral zone of Lake Baikal. Hydrobiological Journal 52: 17-26.

Churilova T., Suslin V., Sosik H.M. et al. 2018. Phytoplankton light absorption in the deep chlorophyll maximum layer of the Black Sea. European Journal of Remote Sensing. DOI: $10.1080 / 22797254.2018 .1533389$

Churilova T., Suslin V., Krivenko O. et al. 2017. Light absorption by phytoplankton in the upper mixed layer of the Black Sea: Seasonality and Parametrization. Frontiers in Marine Science 4: 90. DOI: 10.3389/fmars.2017.00090.

Fietz S., Kobanova G., Izmest'eva L. et al. 2005. Regional, vertical and seasonal distribution of phytoplankton and photosynthetic pigments in Lake Baikal. Journal of Plankton Research 27: 793-810. DOI: 10.1093/plankt/fbi054

Guide to hydrobiological monitoring of freshwater ecosystems. 1992. In: Abakumova V.A. (Ed.). St. Petersburg: Hydrometeoizdat. (in Russian)
Hampton S.E., Izmest'eva L.R., Moore M.V. et al. 2008. Sixty years of environmental change in the world's largest freshwater lake - Lake Baikal, Siberia. Global Change Biology 14: 1947-1958. DOI: 10.1111/j.1365-2486.2008.01616.x

Jeffrey S.W., Humphrey G.F. 1975. New spectrophotometric equations for determining chiorophylls a, b, c1 and c2 in higher plants, algae and phytoplankton. Biochemie und physiologie der pflanzen 167: 191-194.

Jeffrey S.W., Mantoura R.F.C., Wright S.W. 1997. Phytoplankton Pigments in Oceanography. UNESCO, Paris.

Kiselev I.A. 1969. Plankton of the seas and continental waters. Leningrad: Science Publishing House. (in Russian)

Kishino M., Takahashi M., Okami N. et al. 1985. Estimation of the spectral absorption coefficients of the phytoplankton in the sea. Bulletin of marine science 37: 634-642.

Lorenzen C.J. 1967. Determination of chlorophyll and pheopigments: spectrophotometric equations. Limnology and Oceanography 12: 343-346.

Makarova I.V., Pichkily L.O. 1970. To some questions of the methodology for phytoplankton biomass calculation. Botanical journal 55: 1488-1495. (in Russian)

Mitchell B.G. 1990. Algorithms for determining the absorption coefficient of aquatic particulates using the quantitative filter technique (QFT). Ocean optics X. - International Society for Optics and Photonics 1302: 137-149.

Mitchell B.G., Kahru M., Wieland J. et al. 2002. Determination of spectral absorption coefficients of particles, dissolved material and phytoplankton for discrete water samples. In: Fargion G.S., Mueller J.L. (Eds.), Ocean Optics Protocols for Satellite Ocean Color Sensor Validation, NASA/ TM-2002-210004/Rev3-Vol2. NASA Goddard Space Flight Center, Greenbelt, pp. 231-257.

Sadchikov A.P. 2003. Methods for studying freshwater phytoplankton: a methodological guide. Moscow: Publishing house «University and School». (in Russian)

Six C., Thomas J.-C., Garczarek L. et al. 2007. Diversity and evolution of phycobilisomes in marine Synechococcus spp.: a comparative genomics study. Genome Biology 8: R259. DOI: $10.1186 / g b-2007-8-12-r 259$.

Suslin V., Churilova T. 2016. The Black Sea regional algorithm of separation of light absorption by phytoplankton and colored detrital matter using ocean color scanner's bands from 480-560 nm. International Journal of Remote Sensing 37: 4380-4400.

Timoshkin O.A., Samsonov D.P., Yamamuro M. et al. 2016. Rapid ecological change in the coastal zone of Lake Baikal (East Siberia): Is the site of the world's greatest freshwater biodiversity in danger? Journal of Great Lakes Research 42: 487-497. DOI:10.1016/j.jglr.2016.02.011. 